\title{
The role of protein inhibitor of activated STAT3 and miRNA-18a expressions in breast cancer
}

\author{
Azhar Mohamed Nomair ${ }^{1 *}$, Sanaa Shawky Ahmed ${ }^{2}$, Hanan Mohamed Nomeir ${ }^{3}$, Hazem El Mansy ${ }^{4}$ and \\ Ayman Farouk Mohammed ${ }^{5}$
}

\begin{abstract}
Background: Breast cancer is a disease characterized by progressive genetic abnormalities including mutations in tumor suppressor genes and oncogenes, as well as other chromosomal abnormalities. Protein inhibitor of activated signal transducer and activator of transcription 3 (PIAS3) is a member of the PIAS family of transcriptional modulators; its expression is altered in many cancers. Micro-ribonucleic acid (miRNA)-18a acts as an oncogene by negatively regulating PIAS3 and thus modulating the expression of signal transducer and activator of transcription 3 (STAT3) target genes. The aim of this work is to examine the expression levels of PIAS3 gene and miRNA-18a in breast cancer tissues and nearby non-tumor tissues. The samples of breast cancer and paired samples of noncancerous tissue from the same resected breast were obtained from 25 patients undergoing surgery. Full history taking, complete physical examination, pre-operative fine-needle aspiration cytology or ultrasonic (U/S)-guided core biopsy from the breast mass, final surgical biopsy for pathological examination, and routine laboratory investigations were done. Estrogen receptors (ER), progesterone receptors (PR), and human epidermal growth factor receptor 2 (HER2) status were evaluated. Total RNA extraction followed by real-time reverse transcriptionpolymerase chain reaction (RT-PCR) for quantification of PIAS3 mRNA and miRNA-18a expressions was performed.

Results: The mean value of PIAS3 mRNA fold expression was significantly lower in the tumor group (5.12 \pm 9.85 ) compared to the normal group $(8.38 \pm 17.10)(p=0.040)$. miRNA-18a fold expression was higher among tumor group (3.5 \pm 7.4$)$ than that of normal group $(2.5 \pm 3)$, however, it did not reach the level of statistical significance $(p$ $=0.861$ ). miRNA-18a fold expression had negative significant correlation with PIAS3 mRNA fold expression ( $p=$ 0.018). A significant association was observed between miRNA-18a expression in breast cancer tissues and the pathological grade of the tumor $(p=0.029)$.

Conclusions: The results of this study showed that PIAS3 mRNA and miRNA-18a might be of importance in breast cancer development and pathogenesis, and this may be reflected on the treatment strategies targeting STAT3 pathway. However, further studies with larger sample size are needed to validate these observations.
\end{abstract}

Keywords: Breast cancer, PIAS3, miRNA-18a, Epigenetics

\footnotetext{
* Correspondence: azhar.mohmd@yahoo.com; azhar.mohmd1976@gmail.com

'Department of Chemical Pathology, Medical Research Institute, Alexandria

University, P. B. 21561, 165 El-Horreya Street, El Hadara, Alexandria, Egypt

Full list of author information is available at the end of the article
} 


\section{Background}

Protein inhibitor of activated signal transducer and activator of transcription 3 (STAT3) abbreviated as PIAS3 is a member of the PIAS family of transcriptional modulators. Human PIAS3 gene is located on chromosome 1q21 region and encodes a predicted protein of 619 amino acid polypeptide with a molecular mass of about $68 \mathrm{kD}[1]$.

PIAS3 functions as an endogenous inhibitor of activated STAT3 which is a cytoplasmic transcription factor that is activated by tyrosine phosphorylation, leading to dimerization and translocation into the nucleus [2]. In many cancers, constitutively activated STAT3 is associated with uncontrolled growth signaling and thus plays a crucial role in carcinogenesis and cell proliferation $[3,4]$. PIAS3 protein also acts as a small ubiquitin-like modifier (SUMO)-E3 ligase which catalyzes the covalent attachment of a SUMO protein to specific target substrates. It directly binds to many transcription factors and either blocks or enhances their activity [5].

A previous study [6] demonstrated an absence of PIAS3 protein expression in glioblastoma and showed the inhibition of growth in human glioblastoma cells when PIAS3 levels were replaced. Similarly, another study showed that two thirds of specimens of squamous cell lung cancer displayed low to undetectable levels of PIAS3 by immunohistochemistry [7]. Other workers recognized that PIAS3 was widely expressed in various human tissues and in a majority of tumors including lung, breast, prostate, colorectal, and brain tumors [8].

Breast cancer is a disease determined by progressive genetic abnormalities including mutations in tumor suppressor genes and oncogenes as well as other chromosomal abnormalities [9]. More recent research has established that it may also be driven by epigenetic alterations including the control of gene expression by noncoding RNAs such as microRNAs (miRNA) [10, 11].

PIAS3 was found to be one of the miRNA-18a target genes by searching public databases of microRNA target predictions, such as PicTar, and TargetScan databases which predict targets with different techniques including base pairing, target accessibility, and evolutionary conservation of target site [12].. miRNA-18a belongs to the miRNA 17-92 family of microRNA clusters which contribute to the pathogenesis of a variety of human diseases including cancer. A previous study demonstrated that miRNA-18a acts as an oncogene by negatively regulating PIAS3 and thus modulating expression of STAT3 target genes [13].

In this study, we aimed to examine miRNA-18a and PIAS3 gene expressions in breast cancer tissues and nearby non-tumor tissues that may help in understanding some molecular mechanisms involved in the initiation and progression of this disease and assist in identifying new diagnostic and prognostic markers which may enable better prevention and treatment.

\section{Methods}

Samples of breast cancer and paired samples of non-cancerous tissue from the same resected breast were obtained from 25 patients undergoing surgery at the Medical Research Institute Hospital. Patients with breast cancer were subjected to surgical intervention including conservative breast surgery in 23 patients (92\%) and modified radical mastectomy in the remaining two patients (8\%). The study was approved by the local ethics committee of the Medical Research Institute, in accordance with the Code of Ethics of the World Medical Association (Declaration of Helsinki) for research involving humans, and written informed consent was obtained from all included patients before the acquisition of the tissues, explaining the investigational nature of this study. Obtained tissue samples were immediately placed in Eppendorf tubes with mRNA stabilizing solution (RNA later ${ }^{\ominus}$; Applied Biosystems/ Ambion, USA) and stored frozen at $-80{ }^{\circ} \mathrm{C}$ till mRNA and miRNA isolation. Histological assessments were performed on hematoxylin and eosin-stained sections of formalin-fixed, paraffin-embedded tumors (Fig. 1).

All patients of this study were subjected to full history taking, complete physical examination, pre-operative fine-needle aspiration cytology or U/S-guided core biopsy from the breast mass and final surgical biopsy for pathological examination. Pre-operative routine laboratory investigations were done including complete blood count, fasting blood sugar, liver and kidney functions, and also radiological examination including mammography, U/S of both breasts, abdominal and pelvic U/S, chest $\mathrm{X}$-ray, and bone scan were evaluated in all patients.

Postoperative pathological examination including the pathological type, the grade of the tumor, and the presence/absence of lymphovascular invasion as well as hormonal receptors status including estrogen receptors (ER), progesterone receptors (PR), and human epidermal growth factor receptor 2 (HER2) were done. Clinical staging was performed according to the tumor-node-metastasis classification system (TNM) [14]. Seven patients (28\%) were stage IA, nine patients (36\%) were stage IIA, four patients $(16 \%)$ were stage IIB, three patients $(12 \%)$ were of stage IIIA, and two patients $(8 \%)$ were of stage IIIC.

\section{Evaluation of ER, PR, and HER2 Status}

Tissue sections (4-5- $\mathrm{m}$ thick) from paraffin blocks were used for immunohistochemistry (IHC) analyses for evaluation of ER, PR, and HER2 status [15]. Anti-ER (clone ER1D5, Immunotech) and anti-PR (clone 1A6, Immunotech) were used for the detection of ER and PR, respectively. The ER and PR status were interpreted 


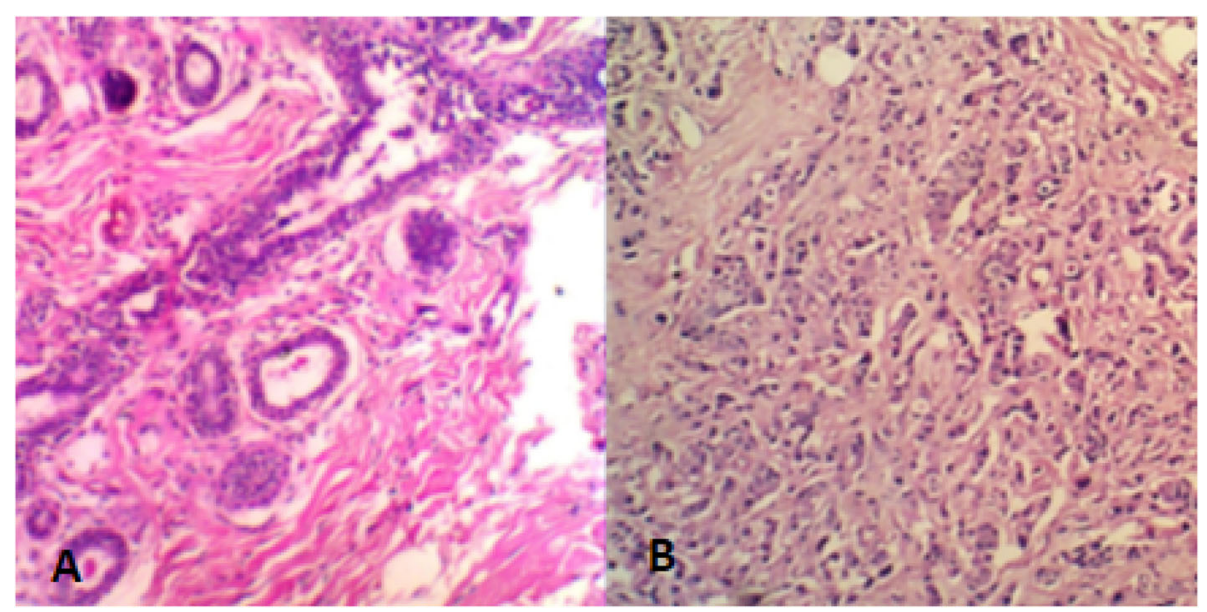

Fig. 1 a Normal breast lobules $(H \& E \times 100)$ versus $\mathbf{b}$ invasive ductal carcinoma grade II showing cords and trabeculae of malignant ductal cells infiltrating desmoplastic stroma $(H \& E \times 100)$

semi-quantitatively as positive when $>1 \%$ of tumor cells showed positive nuclear staining. Tumors were considered to be HER 2 positive only if they were scored $3+$ by IHC or $2+$ by IHC in combination with HER 2 amplification (ratio $>2.0$ ) by fluorescence in situ hybridization.

\section{RNA extraction}

Total RNA including small RNAs and mRNAs were extracted from $50 \mathrm{mg}$ fresh cancer breast tissue or its paired normal tissue using QIAGEN miRNeasy Mini Kit (Cat No. 217004) according to specified instructions, then total RNA was further diluted with $50 \mu \mathrm{L}$ RNase free water. Total RNA concentration and purity were measured with the NanoDrop ND-1000 (NanoDrop, Wilmington, DE, USA), and samples were stored at $-80^{\circ} \mathrm{C}$.

\section{RT-PCR quantification}

Reverse transcription reaction was performed on $100 \mathrm{ng}$ total RNA using miScript Reverse Transcriptase Mix (miScript PCR starter kit (Cat. No. 218193)) according to the manufacturer's instructions (QIAGEN). The newly synthesized complementary DNA (cDNA) was diluted and divided into two Eppendorfs; one for miRNA$18 \mathrm{a}$ assay and the other for PIAS3 mRNA assay. The PCR amplification was performed and the reaction setup of quantitative PCR (qPCR) was prepared as follows: $12.5 \mu \mathrm{L} 2 \mathrm{x}$ Quanti Tect SYBR Green PCR master mix, $2.5 \mu \mathrm{L} 10 \mathrm{x}$ miScript Universal Primer (Cat. No. 218193), $2.5 \mu \mathrm{L}$ miRNA-18a miScript Primer Assay (Cat. No. 218300), or $2.5 \mu \mathrm{L}$ PIAS-3 mRNA Quanti Tect Primer Assay (Cat. No. 249900) for miRNA-18a and PIAS-3 mRNA assays, respectively, and $2.5 \mu \mathrm{L}$ template cDNA were mixed together, then nuclease-free water was added to reach a final volume of $25 \mu \mathrm{L}$.
The housekeeping Human RNU6B (RNU6-2) miScript Primer Assay was used as an internal reference for both miRNA-18a and PIAS3 mRNA assays. The cycling conditions were as follows: one cycle for PCR initial activation step at $95^{\circ} \mathrm{C}$ for $15 \mathrm{~min}$, then $40 \mathrm{cy}$ cles at $94^{\circ} \mathrm{C}$ for $15 \mathrm{~s}$ (denaturation), and $55^{\circ} \mathrm{C}$ for 30 $\mathrm{s}$ (annealing), and $70^{\circ} \mathrm{C}$ for $30 \mathrm{~s}$ (extension). Raw $\mathrm{Ct}$ values were collected using the software supplied with the real-time PCR instrument (Rotor-Gene Q (Qiagen) Software 2.3.1.49) (Fig. 2). The difference of the $\mathrm{Ct}$ value $(\Delta \mathrm{Ct})$ between the target gene and the housekeeping gene for each sample was calculated, and the calibrated $\Delta \mathrm{Ct}$ value $(\Delta \Delta \mathrm{Ct})$ for each sample was calculated $(\Delta \Delta \mathrm{Ct}=\Delta \mathrm{Ct}$ target gene $-\Delta \mathrm{Ct}$ control samples). The relative gene copy number was calculated by the expression $2^{-\Delta \Delta C t}[16]$.

\section{Statistical methods}

Data were fed to the computer and analyzed using IBM SPSS software package version 20.0. (Armonk, NY: IBM Corp). The Kolmogorov-Smirnov test was used to verify the normality of distribution. Qualitative data were described using numbers and percent. Quantitative data were described using range (minimum and maximum), mean, standard deviation, and median. The significance of the obtained results was judged at the 5\% level. For abnormally distributed quantitative variables, MannWhitney test was used to compare between two studied groups, Kruskal-Wallis test was used to compare between more than two studied groups, Wilcoxon signed-rank test was used to compare between two related samples, and Spearman coefficient was used to correlate between two distributed abnormally quantitative variables. 


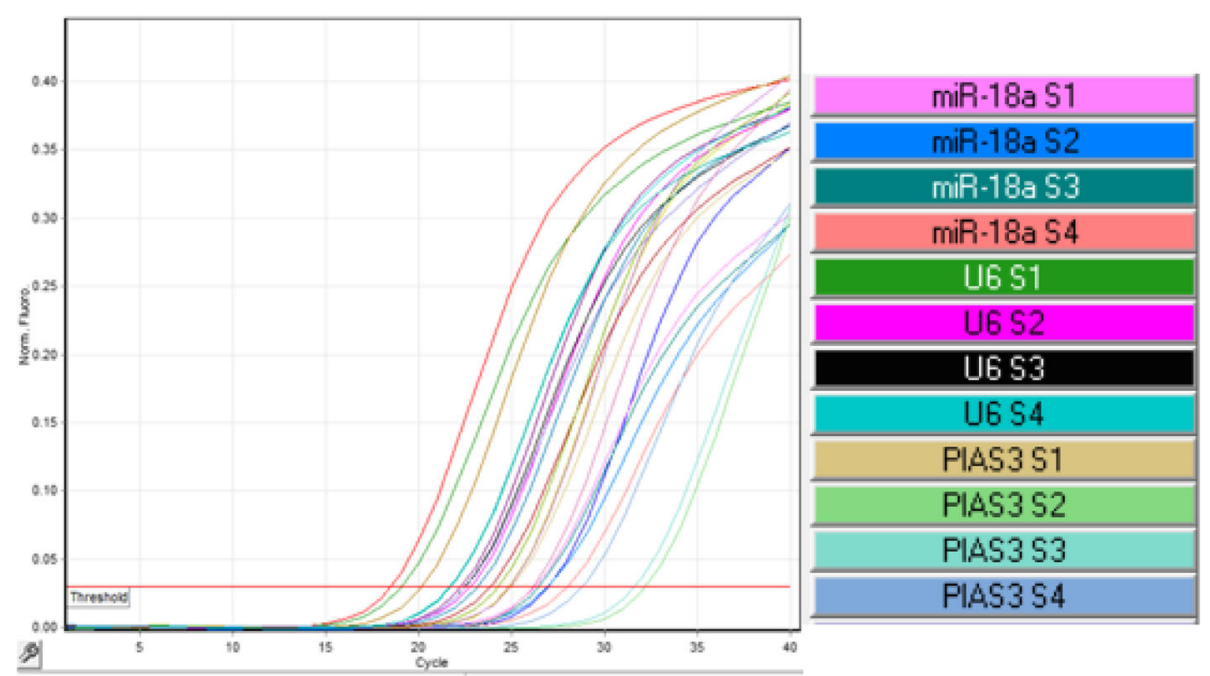

Fig. 2 Amplification plot produced in real-time PCR. S1, S2, S3, S4 for samples no. 1, 2, 3, and 4

\section{Results}

The study was done on 25 samples of breast cancer tissue (Tumor group) and 25 paired samples of non-cancerous tissue (Normal group) from the same resected breast. Table 1 shows the clinicopathological characteristics of the studied patients. Fifty-two percent of patients were above 50 years, while $48 \%$ were below or equal to 50 years. Regarding the histopathological type, $80 \%$ of patients were invasive ductal carcinoma (IDC), 4\% invasive lobular carcinoma (ILC), while $16 \%$ were ductal carcinoma in situ (DCIS).

The comparison between both groups regarding PIAS3 mRNA fold expression and miRNA-18a fold expression was shown in Table 2. The mean PIAS3 mRNA fold expression was significantly lower in tumor group $(5.12 \pm 9.85)$ compared to normal group $(8.38 \pm 17.10)$, $(p=0.040)$, while the mean value of miRNA-18a fold expression among tumor group $(3.5 \pm 7.4)$ was higher than that of normal group $(2.5 \pm 3)$; however, it did not reach the level of statistical significance $(p=0.861)$.

As regards the correlation between PIAS3 mRNA fold expression and miRNA-18a fold expression in the studied groups, miRNA-18a fold expression had a negative significant correlation with PIAS3 mRNA fold expression $(p=0.018)$ (Fig. 3).

The expression of PIAS3 mRNA and miRNA-18a were tested for the association with the clinicopathological data of the studied patients (Table 3). No association was found between the PIAS3 mRNA expression in the tumor group and patient's age, focality, tumor size, histopathological type, pathological grade, lymphovascular invasion, lymph node metastasis, TNM staging, ER, PR, HER2 or the molecular type. However, a significant association was observed between miRNA-18a expression in breast cancer tissues and the pathological grade of the tumor $(p=0.029)$.

\section{Discussion}

Numerous genetic and epigenetic changes are involved in tumorigenesis and the progression of various cancers including breast cancer [17]. PIAS3 a modulator of DNA-binding transcription factors was originally identified as a specific inhibitor of the STAT3 signaling pathway which was hyper-activated in various cancers and has been cited in the pathogenesis of breast cancer [18]. Now, it is well recognized that the PIAS family regulates a variety of cytokines and transcription factors with downstream alterations in apoptosis, angiogenesis, and a number of signaling pathways [19].

PIAS3 gene was shown to be a target of many epigenetic modifications including microRNAs. miRNA-18a was found to be a modulator of STAT3 activity through negative regulation of PIAS3 during gastric adenocarcinogenesis, and it was shown that miRNA-18a suppress their targets in response to different environmental stimuli, which may or may not favor cancer [20]. To clarify the role of PIAS3 and miRNA-18a in breast cancer, we analyzed the expression of PIAS3 mRNA and miRNA18a in 25 tissue samples of breast cancer (Tumor group) and 25 paired samples of non-cancerous tissue from the same resected breast (Normal group), and they were statistically analyzed along with the clinicopathological data of the studied patients.

In the current work, PIAS3 mRNA expression was significantly downregulated in the tumor group compared to the normal group $(p=0.040)$. In agreement with this, Chandhoke et al. [21] revealed that reduction of PIAS3 might be important for the invasive behavior of breast cancer cell-derived organoids via sumoylation of Smurf2, and they suggested that PIAS3 and Smurf2 may serve as biologically relevant biomarkers in human breast cancer. In addition, Yang et al. [22] found that the total PIAS3 
Table 1 The clinicopathological characteristics of studied patients

\begin{tabular}{|c|c|c|}
\hline Variables & $\begin{array}{l}\text { Patients } \\
(n=25)\end{array}$ & $(\%)$ \\
\hline \multicolumn{3}{|l|}{ Age (years) } \\
\hline$>50$ & 13 & 52 \\
\hline$\leq 50$ & 12 & 48 \\
\hline \multicolumn{3}{|l|}{ Focality } \\
\hline Unifocal & 23 & 92 \\
\hline Multifocal & 2 & 8 \\
\hline \multicolumn{3}{|l|}{ Tumor size } \\
\hline$<2 \mathrm{~cm}$ & 14 & 56 \\
\hline$\geq 2 \mathrm{~cm}$ & 11 & 44 \\
\hline \multicolumn{3}{|c|}{ Histopathological type } \\
\hline IDC & 20 & 80 \\
\hline ILC & 1 & 4 \\
\hline DCIS & 4 & 16 \\
\hline \multicolumn{3}{|l|}{ Pathological grade } \\
\hline Gl & 4 & 16 \\
\hline Gll & 15 & 60 \\
\hline GIII & 6 & 24 \\
\hline \multicolumn{3}{|c|}{ Lymphovascular invasion } \\
\hline Negative & 3 & 12 \\
\hline Positive & 22 & 88 \\
\hline \multicolumn{3}{|l|}{ LN metastasis } \\
\hline No & 12 & 48 \\
\hline Yes & 13 & 52 \\
\hline \multicolumn{3}{|l|}{ TNM stage } \\
\hline IA & 7 & 28 \\
\hline$\|A+\| B$ & 13 & 52 \\
\hline III & 5 & 20 \\
\hline \multicolumn{3}{|l|}{ ER } \\
\hline Positive & 19 & 76 \\
\hline Negative & 6 & 24 \\
\hline \multicolumn{3}{|l|}{$P R$} \\
\hline Positive & 19 & 76 \\
\hline Negative & 6 & 24 \\
\hline \multicolumn{3}{|l|}{ HER2 } \\
\hline Positive & 20 & 80 \\
\hline Negative & 5 & 20 \\
\hline \multicolumn{3}{|l|}{ Molecular type } \\
\hline Luminal A & 5 & 20 \\
\hline Luminal B & 14 & 56 \\
\hline HER2 enriched & 6 & 24 \\
\hline
\end{tabular}

$n$ number, $L N$ lymph node, $E R$ estrogen receptors, $P R$ progesterone receptors, HER2 epidermal growth factor receptor 2, TNM tumor-node-metastasis classification system
Table 2 PIAS3 mRNA fold expression and miRNA-18a fold expression in the studied groups

\begin{tabular}{lllll}
\hline & Tumor group & Normal group & $Z$ & $p$ value \\
\hline PIAS3 mRNA & & & & \\
Median (Min-Max) & $0.77(0.03-36.0)$ & $0.89(0.0-66.72)$ & $2.059^{*}$ & $0.040^{*}$ \\
Mean \pm SD & $5.12 \pm 9.85$ & $8.38 \pm 17.10$ & & \\
miRNA-18a & & & & \\
Median (Min-Max) & $0.7(0.1-34)$ & $1.4(0-12.2)$ & 0.175 & 0.861 \\
Mean \pm SD & $3.5 \pm 7.4$ & $2.5 \pm 3$ & & \\
\hline
\end{tabular}

$Z$ Wilcoxon signed-rank test which is used to compare between two related samples, Min minimum, Max maximum, $S D$ standard deviation *Statistically significant at $p \leq 0.05$

$p$ value for comparing between the studied groups

protein decreased in $62 \%$ of breast cancer tissues compared with that in the adjacent non-cancerous tissues. Consistently, lower PIAS3 expression has also been observed in various cancers. Liu et al. [23] revealed that the expression levels of PIAS3 protein and mRNA were significantly lower in gastric cancerous tissues than in its adjacent non-tumor tissues, and also lower in gastric cancer cell lines. Kluge et al. [19] found that the expression of PIAS3 is variable in lung cancer cell lines with 2 of 3 squamous cell carcinoma cell lines having no or little PIAS3 protein expression, and they found the majority of human small cell carcinoma of the lung lack PIAS3 expression by immunohistochemistry.

On the contrary, McHale et al. [24] showed a substantial increase in the expression of PIAS3 protein levels in malignant breast tissues as compared to benign/hyperplastic epithelium. In addition, Wang et al. [8] observed increased PIAS3 expression in 100/103 samples examined in a variety of human cancers including lung, breast, prostate, colon-rectum, and brain tumors.

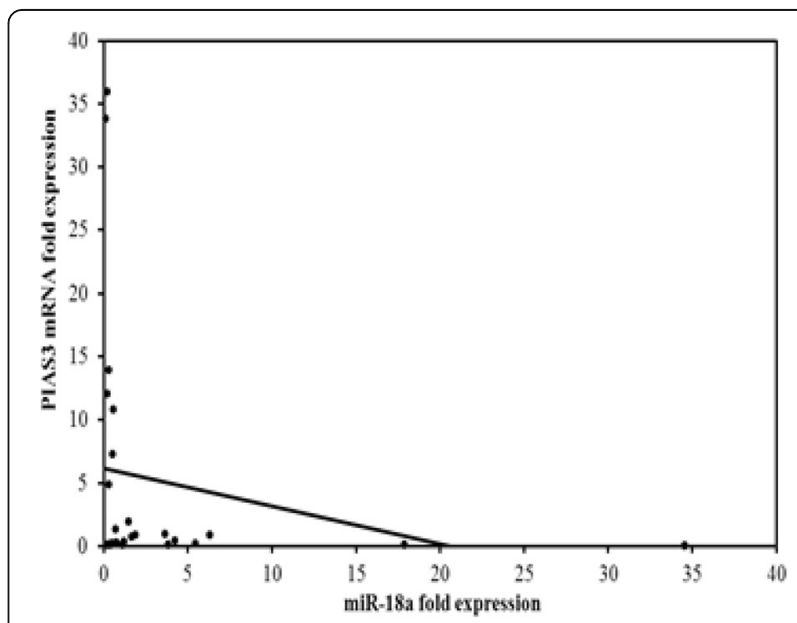

Fig. 3 Correlation between PIAS3 mRNA fold expression and miRNA-18a fold expression in the studied patients. Legend: $r=$ $0.469, p=0.018$ 
Table 3 Association between PIAS3 fold expression and miRNA-18a fold expression and clinicopathological characteristics of studied patients

\begin{tabular}{|c|c|c|c|c|c|c|}
\hline Variables & $\begin{array}{l}\text { miRNA-18a } \\
\text { Median (Min-Max) }\end{array}$ & $\mathrm{U} / \mathrm{H}$ & $p$ value & $\begin{array}{l}\text { PIAS3 } \\
\text { Median (Min-Max) }\end{array}$ & $\mathrm{U} / \mathrm{H}$ & $p$ value \\
\hline \multicolumn{7}{|l|}{ Age } \\
\hline$>50$ & $1.7(0.1-34.5)$ & 53.50 & 0.202 & $0.7(0.0-36.0)$ & $U=75.0$ & 0.936 \\
\hline$\leq 50$ & $0.6(0.2-3.6)$ & & & $0.8(0.1-12.0)$ & & \\
\hline \multicolumn{7}{|l|}{ Focality } \\
\hline Unifocal & $0.7(0.1-34.5)$ & 20.50 & 0.807 & $0.5(0.0-36.0)$ & $U=13.0$ & 0.373 \\
\hline Multifocal & $2.1(0.5-3.6)$ & & & $4.1(0.9-7.3)$ & & \\
\hline \multicolumn{7}{|l|}{ Tumor size } \\
\hline$<2 \mathrm{~cm}$ & $0.7(0.1-34.5)$ & 63.00 & 0.467 & $0.8(0.0-36.0)$ & $U=70.0$ & 0.727 \\
\hline$\geq 2 \mathrm{~cm}$ & $1.1(0.3-17.9)$ & & & $0.5(0.1-13.9)$ & & \\
\hline \multicolumn{7}{|c|}{ Histopathological type } \\
\hline IDC & $0.7(0.1-17.9)$ & 36.00 & 0.794 & $0.6(0.1-36.0)$ & $U=36.0$ & 0.794 \\
\hline ILC & 3.6 & & & 0.9 & & \\
\hline Others & $2.0(0.3-34.5)$ & & & $2.5(0.0-13.9)$ & & \\
\hline \multicolumn{7}{|l|}{ Pathological grade } \\
\hline Gl & $2.0(0.3-34.5)$ & $4.758^{*}$ & $0.029^{*}$ & $2.51(0.0-13.9)$ & $H=2.397$ & 0.302 \\
\hline Gll & $0.6(0.1-6.3)$ & & & $0.9(0.1-36.0)$ & & \\
\hline GIII & $3.1(0.4-17.9)$ & & & $0.3(0.1-0.9)$ & & \\
\hline \multicolumn{7}{|c|}{ Lymphovascular invasion } \\
\hline Negative & $3.8(0.3-34.5)$ & 21.500 & 0.353 & $0.15(0.03-13.93)$ & $U=23.0$ & 0.446 \\
\hline Positive & $0.7(0.1-17.9)$ & & & $0.84(0.13-36.0)$ & & \\
\hline \multicolumn{7}{|l|}{ LN metastasis } \\
\hline No & $0.6(0.2-34.5)$ & 74.5 & 0.852 & $0.41(0.03-36.0)$ & $U=67.50$ & 0.574 \\
\hline Yes & $1.1(0.1-6.3)$ & & & $0.90(0.14-33.82)$ & & \\
\hline \multicolumn{7}{|l|}{ TNM stage } \\
\hline 0 & 34.5 & 1.744 & 0.418 & 0 & $H=3.008$ & 0.390 \\
\hline IA & $0.5(0.2-3.8)$ & & & $0.9(0.1-36.0)$ & & \\
\hline$\|A+\| B$ & $1.5(0.2-17.9)$ & & & $0.8(0.1-12.0)$ & & \\
\hline III & $0.7(0.1-3.6)$ & & & $0.9(0.1-33.8)$ & & \\
\hline \multicolumn{7}{|l|}{ ER } \\
\hline Positive & $0.7(0.1-34.5)$ & 36.00 & 0.371 & $0.8(0.0-36.0)$ & $U=43.0$ & 0.668 \\
\hline Negative & $1.9(0.4-5.5)$ & & & $0.5(0.1-10.9)$ & & \\
\hline \multicolumn{7}{|l|}{$P R$} \\
\hline Positive & $0.7(0.1-34.5)$ & 36.00 & 0.371 & $0.8(0.0-36.0)$ & $U=43.0$ & 0.668 \\
\hline Negative & $1.9(0.4-5.5)$ & & & $0.5(0.1-10.9)$ & & \\
\hline \multicolumn{7}{|l|}{ HER2 } \\
\hline Positive & $0.9(0.1-34.5)$ & 49.50 & 0.974 & $0.6(0.0-36.0)$ & $U=48.0$ & 0.921 \\
\hline Negative & $0.7(0.2-17.9)$ & & & $1.3(0.1-7.3)$ & & \\
\hline \multicolumn{7}{|l|}{ Molecular type } \\
\hline Luminal A & $0.7(0.2-17.9)$ & 0.985 & 0.611 & $1.3(0.1-7.3)$ & $H=0.296$ & 0.863 \\
\hline Luminal B & $0.7(0.1-34.5)$ & & & $0.8(0.0-36.0)$ & & \\
\hline HER2 enriched & $1.9(0.4-5.5)$ & & & $0.5(0.1-10.9)$ & & \\
\hline
\end{tabular}

$U$ Mann-Whitney $U$ test which was used to compare between two studied groups, $H$ for Kruskal-Wallis $H$-test which was used to compare between more than two studied groups, $L N$ lymph node, ER estrogen receptors $P R$ progesterone receptors, HER2 epidermal growth factor receptor 2, TNM tumor-node-metastasis classification system. Min minimum, Max maximum

*Statistically significant at $p \leq 0.05$

$p$ value for comparing between the studied groups 
PIAS proteins act as small ubiquitin-like modifier E3 ligases, and sumoylation of transcription factors can significantly alter their function and their intranuclear localization. By acting as inhibitors of DNA binding, mediators of sumoylation, and/or recruiters of coregulatory proteins, PIAS family members can significantly modify the function of transcription factors that include members of the STAT family, promoting the oncogenic effects of their activation. A previous study showed that PIAS3 overexpression in breast cancer cell lines can significantly modulate STAT5-mediated gene expression and induce cellular apoptosis [24]. In addition, PIAS3 has a vast STAT3-independent effect by binding to a number of transcription factors with downstream alterations in apoptosis, angiogenesis, and a number of signaling pathways, for instance, it interacts with nuclear hormone receptors, androgen receptors, estrogen receptors, p53, BRCA1, and metastasis tumor antigen [25].

MicroRNAs play a critical role in the carcinogenesis and progression of breast cancer, whereas miRNA-18a has both oncogenic and tumor-suppressive roles [20]. Guo et al. [26] showed that miRNA-18a was underexpressed in human breast cancer, and thought to have a role as a tumor suppressor. In addition, Krutilina et al. [27] showed in their animal model that high expression of miRNA-18a had led to decreased spontaneous lung metastasis and tumor growth and increased apoptosis in vitro in response to hypoxic and acidotic conditions, supporting its role as a tumor suppressor.

In contrast, Yoshimoto et al. [28] showed in their study on 171 breast cancer samples that miRNA-18a was overexpressed in estrogen receptor-negative breast tumors which implicates that it is an oncogene. Also, Mouw et al. [29] showed that miRNA-18a was upregulated in basal-like breast cancers and its expression correlated with increased future disease aggression for patients with luminal breast cancers identifying miRNA18 a a mechanically regulated tumor enhancer.

In the present work, miRNA-18a was overexpressed in the tumor group compared to the normal group, but it was not statistically significant $(p=0.861)$ (Table 2$)$, and this result favored its oncogenic role.

In the present study, miRNA-18a expression was negatively correlated with PIAS3 mRNA expression $(r=-$ 0.469, $p=0.018$ ) (Fig. 3), and this favors that PIAS3 mRNA may be a target to miRNA-18a. Pichiorri et al. [30] showed that miRNA derived from the miRNA-17-92 cluster including miRNA-18a modulated STAT3 phosphorylation in multiple myeloma cells. In addition, Shuai et al. [31] found that under physiological conditions, the activation of STAT proteins is rapid and transient because of negative regulation by proteins such as SOCS and PIAS3. Activated STAT3 protects tumor cells from apoptosis and promotes the expression of cell proliferation- associated proteins, such as Bcl-xL, Mcl-1, Bcl-2, Fas, cyclin D1, Survivin, and c-Myc [32]. Wu et al. [13] speculated that miRNA-18a might target a negative regulator of the STAT3 signaling pathway and determined that the 3 '-untranslated region of PIAS3 contains a potential binding site for miRNA-18a and that miRNA-18a could directly target PIAS3 in tumor cell line.

We next examined the association of the expression levels of both PIAS3 mRNA, and miRNA-18a, and the clinicopathological characteristics of the studied patients (Table 3). Only miRNA-18a fold expression was positively correlated with the grade of the tumor $(p=0.029)$. This was in agreement with $\mathrm{Wu}$ et al. [33] who found that miRNA-18a was highly expressed in high-grade gliomas. Also Blenkiron et al. [34] revealed that miRNA18a was overexpressed in grade III tumors. In addition, Motoyama et al. [35] revealed that miRNA-18a overexpression was associated with poor prognosis in human colorectal cancer. Together, these findings provide a support that miRNA-18a may have a role in tumor proliferation and progression and may be used to develop future biomarkers for prognosis of breast cancer.

\section{Conclusions}

In this study, PIAS3 mRNA fold expression was significantly lower in the tumor group compared to the normal group, while miRNA-18a expression showed non-significant higher expression levels in the tumor group as compared to the normal group. Also, a negative correlation between PIAS3 mRNA and miRNA-18a expressions was statistically significant. Besides, a significant association was observed between miRNA-18a expression in breast cancer tissues and the pathological grade of the tumor. These findings indicate that PIAS3 and miRNA-18a may play a role in breast cancer development and progression, at least in part by negatively regulating PIAS3 by miRNA$18 \mathrm{a}$ and thereby modulating expression of STAT3 target genes, and provide a support that miRNA-18a may be used to develop future biomarker for prognosis of breast cancer. In order to clarify more the role of miRNA-18a and PIAS3 mRNA in breast cancer, further studies looking at the expression patterns of miRNA-18a and its target genes including PIAS3 are needed to be performed, and these results require confirmation in a larger group of breast cancer patients.

\section{Additional file}

Additional file 1: The datasets of the study. (XLSX $24 \mathrm{~kb})$

\section{Abbreviations}

$\Delta \Delta \mathrm{Ct}$ : The calibrated $\Delta \mathrm{Ct}$ value; $\Delta \mathrm{Ct}$ : The difference of the Ct value;

DCIS: Ductal carcinoma in situ; ER: Estrogen receptors; $\mathrm{H}$ : Kruskal-Wallis $\mathrm{H}$ test; HER2: Human epidermal growth factor receptor 2; IDC: Invasive ductal carcinoma; IHC: Immunohistochemistry; ILC: Invasive lobular carcinoma; 
LN: Lymph node; Max: Maximum; Min: Minimum; miRNA: Micro-ribonucleic acid; n: Number; PCR: Polymerase chain reaction; PIAS3: Protein inhibitor of activated STAT3; PR: Progesterone receptors; RT-PCR: reverse transcriptionPCR; SD: Standard deviation; STAT3: Signal transducer and activator of transcription 3; SUMO: Small ubiquitin-like modifier; TNM: Tumor-nodemetastasis classification system; U: Mann-Whitney $U$ test; Z: Wilcoxon signed ranks test

\section{Acknowledgements}

Not applicable

\section{Authors' contributions}

AMN made the literature review, performed the design of the study, carried out the molecular genetic studies, analyzed and interpreted the patient data, and was a major contributor in writing the manuscript. SSA performed the pathological examination of the samples and the immunohistochemistry and revised the manuscript. HMN participated in the design of the study, carried out the molecular genetic studies, and revised the manuscript. HEM participated in writing and revision of the manuscript. AFM provided the surgical specimens and revised the manuscript. All authors read and approved the final manuscript.

\section{Funding}

Not applicable

\section{Availability of data and materials}

The datasets used and analyzed during the current study are available in the Additional file 1.

\section{Ethics approval and consent to participate}

The study was approved by the local ethics committee of the Medical Research Institute, Alexandria University (reference number: IORG 0008812), in accordance with the Code of Ethics of the World Medical Association (Declaration of Helsinki) for research involving humans, and written informed consent was obtained from all included patients before the acquisition of the tissue specimens.

\section{Consent for publication}

Not applicable

\section{Competing interests}

The authors declare that they have no competing interests.

\section{Author details}

'Department of Chemical Pathology, Medical Research Institute, Alexandria University, P. B. 21561, 165 El-Horreya Street, El Hadara, Alexandria, Egypt. ${ }^{2}$ Department of Pathology, Medical Research Institute, Alexandria University, Alexandria, Egypt. ${ }^{3}$ Department of Medical Biochemistry, Faculty of Medicine, Alexandria University, Alexandria, Egypt. ${ }^{4}$ Department of Cancer Management and Research, Medical Research Institute, Alexandria University, Alexandria, Egypt. ${ }^{5}$ Department of Clinical and Experimental Surgery, Medical Research Institute, Alexandria University, Alexandria, Egypt.

\section{Received: 3 June 2019 Accepted: 30 August 2019}

Published online: 05 October 2019

\section{References}

1. Li H, Gao H, Bijukchhe SM, Wang Y, Li T (2013) PIAS3 may represent a potential biomarker for diagnosis and therapeutic of human colorectal cancer. Med Hypotheses. 81(6):1151-1154

2. Schindler CW (2002) Series introduction. JAK-STAT signaling in human disease. J Clin Invest. 109(9):1133-1137

3. Miklossy G, Hilliard TS, Turkson J (2013) Therapeutic modulators of STAT signaling for human diseases. Nat Rev Drug Discov. 12(8):611-629

4. Quintás-Cardama A, Verstovsek S (2013) Molecular pathways: Jak/STAT pathway: mutations, inhibitors, and resistance. Clin Cancer Res. 19(8): 1933-1940

5. Sundvall M, Korhonen A, Vaparanta K, Anckar J, Halkilahti K, Salah Z et a (2012) Protein inhibitor of activated STAT3 (PIAS3) protein promotes SUMOylation and nuclear sequestration of the intracellular domain of ErbB4 protein. J Biol Chem 287(27):23216-23226
6. Brantley EC, Nabors LB, Gillespie GY, Choi YH, Palmer CA, Harrison K et al (2008) Loss of protein inhibitors of activated STAT-3 expression in glioblastoma multiforme tumors: implications for STAT-3 activation and gene expression. Clin Cancer Res. 14(15):4694-7048

7. Abbas R, McColl KS, Kresak A, Yang M, Chen Y, Fu P et al (2015) PIAS3 expression in squamous cell lung cancer is low and predicts overall survival. Cancer Med. 4(3):325-332

8. Wang L, Banerjee S (2004) Differential PIAS3 expression in human malignancy. Oncol Rep. 11(6):1319-1324

9. Shidfar A, Costa FF (2017) Scholtens D4, Bisch of JM, Sullivan ME, Ivancic DZ, et al. Expression of miR-18a and miR-210 in normal breast tissue as candidate biomarkers of breast cancer risk. Cancer Prev Res (Phila) 10(1):89-97

10. O'Day E, Lal A (2010) MicroRNAs and their target gene networks in breast cancer. Breast Cancer Res. 12(2):201

11. Jovanovic J, Rønneberg JA, Tost J, Kristensen V (2010) The epigenetics of breast cancer. Mol Oncol. 4(3):242-254

12. Liu B, Li J, Cairns MJ (2014) Identifying miRNAs, targets and functions. Brief Bioinform. 15(1):1-19

13. Wu W, Takanashi M, Borjigin N, Ohno SI, Fujita K, Hoshino S et al (2013) MicroRNA-18a modulates STAT3 activity through negative regulation of PIAS3 during gastric adenocarcinogenesis. Br J Cancer. 108(3):653-661

14. Edge SB, Byrd DR, Compton CC, Fritz AG, Greene FL, Trotti A (2010) American joint committee on cancer: breast. AJCC cancer staging manual, 7th edn. Springer, New York, NY, pp 347-376

15. Tokunaga E, Kimura Y, Oki E, Ueda N, Futatsugi M, Mashino K et al (2006 Jan 15) Akt is frequently activated in HER2/neu-positive breast cancers and associated with poor prognosis among hormone-treated patients. Int J Cancer. 118(2):284-289

16. Schmittgen TD, Livak KJ (2008) Analyzing real-time PCR data by the comparative C(T) method. Nat Protoc. 3(6):1101-1108

17. Morimura R, Komatsu S, Ichikawa D, Takeshita H, Tsujiura M, Nagata $\mathrm{H}$ et al (2011) Novel diagnostic value of circulating miR-18a in plasma of patients with pancreatic cancer. Br J Cancer. 105(11):1733-1740

18. Agboola A, Musa A, Banjo A, Ayoade B, Deji-Agboola M, Nolan C et al (2014) PIASY expression in relation to clinicopathological, tumour factors and survival in indigenous black breast cancer women. J Clin Pathol. 67(4):301-306

19. Kluge A, Dabir S, Vlassenbroeck I, Eisenberg R, Dowlati A (2011) Protein inhibitor of activated STAT3 expression in lung cancer. Mol Oncol. 5(3): 256-264

20. Kim SY, Kawaguchi T, Yan L, Young J, Qi Q, Takabe K (2017) Clinical relevance of microRNA expressions in breast cancer validated using the Cancer Genome Atlas (TCGA). Ann Surg Oncol. 24(10):2943-2949

21. Chandhoke AS, Chanda A, Karve K, Deng L, Bonni S (2017) The PIAS3Smurf2 sumoylation pathway suppresses breast cancer organoid invasiveness. Oncotarget. 8(13):21001-21014

22. Yang SF, Hou MF, Chen FM, Ou-Yang F, Wu YC, Chai CY et al (2016) Prognostic value of protein inhibitor of activated STAT3 in breast cancer patients receiving hormone therapy. BMC Cancer. 16:20

23. Liu LM, Yan MG, Yang DH, Sun WW, Zhang JX (2011) PIAS3 expression in human gastric carcinoma and its adjacent non-tumor tissues. Clin Res Hepatol Gastroenterol. 35(5):393-398

24. McHale K, Tomaszewski JE, Puthiyaveettil R, Livolsi VA, Clevenger CV (2008) Altered expression of prolactin receptor-associated signaling proteins in human breast carcinoma. Mod Pathol. 21(5):565-571

25. Dabir S, Kluge A, Aziz MA, Houghton JA, Dowlati A (2011) Identification of STAT3-independent regulatory effects for protein inhibitor of activated STAT3 by binding to novel transcription factors. Cancer Biol Ther. 12(2):139-151

26. Guo X, Yang C, Qian X, Lei T, Li Y, Shen H et al (2013) Estrogen receptor a regulates ATM Expression through miRNAs in breast cancer. Clin Cancer Res. 19(18):4994-5002

27. Krutilina R, Sun W, Sethuraman A, Brown M, Seagroves TN, Pfeffer LM et al (2014) MicroRNA-18a inhibits hypoxia-inducible factor 1a activity and lung metastasis in basal breast cancers. Breast Cancer Res. 16(4):R78

28. Yoshimoto $N$, Toyama T, Takahashi S, Sugiura H, Endo $Y$, Iwasa M et al (2011) Distinct expressions of microRNAs that directly target estrogen receptor a in human breast cancer. Breast Cancer Res Treat. 130(1):331-339

29. Mouw JK, Yui Y, Damiano L, Bainer RO, Lakins JN, Acerbi I et al (2014) Tissue mechanics modulate microRNA-dependent PTEN expression to regulate malignant progression. Nat Med. 20(4):360-367 
30. Pichiorri F, Suh SS, Ladetto M, Kuehl M, Palumbo T, Drandi D et al (2008) MicroRNAs regulate critical genes associated with multiple myeloma pathogenesis. Proc Natl Acad Sci U S A. 105(35):12885-12890

31. Shuai K, Liu B (2005) Regulation of gene-activation pathways by PIAS proteins in the immune system. Nat Rev Immunol. 5:593-605

32. Yu H, Jove R (2004) The STATs of cancer--new molecular targets come of age. Nat Rev Cancer. 4(2):97-105

33. Wu W, Zhou X, Yu T, Bao Z, Zhi T, Jiang K et al (2017) The malignancy of miR-18a in human glioblastoma via directly targeting CBX7. Am J Cancer Res. 7(1):64-76

34. Blenkiron C, Goldstein LD, Thorne NP, Spiteri I, Chin SF, Dunning MJ et al (2007) MicroRNA expression profiling of human breast cancer identifies new markers of tumor subtype. Genome Biol. 8(10):R214

35. Motoyama K, Inoue H, Takatsuno Y, Tanaka F, Mimori K, Uetake $\mathrm{H}$ et al (2009) Over- and under-expressed microRNAs in human colorectal cancer. Int J Oncol. 34(4):1069-1075

\section{Publisher's Note}

Springer Nature remains neutral with regard to jurisdictional claims in published maps and institutional affiliations.

\section{Submit your manuscript to a SpringerOpen ${ }^{\mathcal{O}}$ journal and benefit from:}

- Convenient online submission

- Rigorous peer review

- Open access: articles freely available online

- High visibility within the field

- Retaining the copyright to your article

Submit your next manuscript at $\boldsymbol{\nabla}$ springeropen.com 